\title{
Facultades de los Alcaldes en la nueva Ley de Orden Público
}

\author{
por \\ FRANCISCO LOBATO BRIME \\ Doctor en Derecho
}

INTRODUCCIÓN

Con motivo de la reciente promulgación de la Ley de la Jefatura del Estado de 30 de julio de 1959, de Orden Público, número 45 , nos ha parecido oportuno exponer algunas consideraciones sobre las facultades de los Alcaldes contenidas en la misma. Dada su especialización y el público a que va dirigida, nos parece materia interesante la elegida, porque a nuestro modo de ver, este tema es en el orden local el primero en importancia entre los regulados por la reciente Ley. De esta manera, queremos que nuestro trabajo goce de la concreción, pero a la vez nuestro máximo deseo es señalar, en rasgos precisos y definidos, todas las atribuciones que en materia de orden público se conceden a nuestros Alcaldes en la legislación vigente; en atención a lo dicho nos parece obligado referirnos, aunque sólo sea de pasada, a la vigente Ley de Régimen local, texto refundido de 24 de junio de 1955, ya que dos preceptos de la misma se refieren a las facultades de los Alcaldes en lo concerniente al orden público.

La nueva Ley de Orden Público procura, como se dice en su Preámbulo, fundir armónicamente el viejo material heredado, que ha mantenido su prestigio a través de la prueba histó- 
rica, con las tendencias modernas sobre esta materia, y de este modo trata de confeccionar un instrumento jurídico capaz de afrontar con las máximas garantías de acierto las necesidades de la paz pública nacional.

Orden y paz públicas son a nuestro modo de ver los dos puntos claves que se pretenden lograr con la promulgación de esta nueva Ley. No olvidemos que sobre los conceptos de paz y orden se basó la Cristiandad y el Imperio medieval, ejemplos patentes de bienestar y tranquilidad social. Cuando este orden se resquebraja, la paz se quiebra, afloran las pasiones politicas, $y$, en definitiva, la organización política, social, económica y jurídica entra en crisis. Por eso, no nos sorprende que nuestro legislador tenga una honda preocupación por mantener el orden y la paz constituídas dentro de un Estado legal y social de Derecho. La reforma de la estructura política de un país ha de hacerse normalmente por los medios legalmente autorizados y a tenor de los progresos que se verifican en la vida social $y$ política. Aparece, por consiguiente, plenamente justificada la promulgación de la nueva Ley de Orden Público, que reforma la de 28 de julio de $\mathbf{1 9 3 3}$. Dicha reforma se centra en la definición precisa y actual del orden público, en la delimitación orgánica y unitaria del instrumento encargado de velar por él, ya que se restringen las facultades sancionadoras de las Autoridades gubernativas en las infracciones que se cometan contra el orden público. Por otra parte, en la Ley se hace un desarrollo, rigurosamente sistemático, de estos estados vitales o de crisis, reduciéndolos a los de excepción y guerra; se procura determinar en cada uno de ellos los medios y el alcance de las facultades que se confieren a las Autoridades gubernativas para afrontar y resolver las situaciones de emergencia que se les presenten con la mínima intromisión en el libre ejercicio de los derechos personales que éstas consientan.

- Finaliza el Preámbulo de esta Ley con las siguientes palabras: "Con todo lo hecho se puede afirmar que se ofrece una versión nueva, por lo renovada, de la anterior Ley de Orden Público, para garantizar la paz y seguridad públicas en el seno 
de la Nación libre y unida". La Ley de Orden Público es, por tanto, preventiva. Regula las situaciones anormales de excepción y guerra, si por desgracia alguna vez surgiesen, y da unas normas tendentes a garantizar la paz y seguridad públicas en estas situaciones de anormalidad, con el fin de que no se quebranten la unidad y libertad de nuestra Nación, cuyo logro ha sido causa de numerosísimos sacrificios.

\section{Los AlCaldes y el MANTENimiento DEL ORDEN PÚblico}

Se dice en el artículo primero de la Ley que constituyen el fundamento del orden público el normal funcionamiento de las Instituciones públicas y privadas, el mantenimiento de la paz interior y el libre y pacífico ejercicio de los derechos individuales, políticos y sociales, reconocidos por las leyes. En el primer concepto de esta enumeración va implicada la base fundamental del orden público. Si las Instituciones públicas y privadas funcionan normalmente, es síntoma cierto de que existe paz interior y respeto hacia los derechos de la persona humana. No se concibe el normal funcionamiento de la vida pública y privada de la Nación sin una perfecta armonía entre gobernantes y gobernados.

De todos conocida es la triple distinción que se hace de las atribuciones que al Alcalde corresponden. Se distinguen las que le competen como Presidente del Ayuntamiento, como Jefe de la Administración municipal y como Delegado del Gobierno.

El artículo 117 de la Ley de Régimen local establece lo siguiente en materia de orden público: "Corresponderá al Alcalde como Delegado del Gobierno en el término municipal:

b) Mantener el orden y proveer a la seguridad pública e individual.

d) Adoptar personalmente y bajo su responsabilidad, en caso de gravedad producida por epidemia, trastornos de orden público, guerra, inundación o cualquier otro accidente análogo, las medidas que juzgue necesarias, dando cuenta inmediata al Gobernador civil y al Ayuntamienton. 
Estas facultades que la Ley de Régimen local asigna a los Alcaldes en materia de orden público, aparecen completadas por las atribuciones que el artículo 124 de la misma Ley asigna al Alcalde pedáneo, al establecer en el apartado $c$ ) que en particular corresponde a éste "auxiliar al Alcalde en el mantenimiento del orden públicon. Esta Ley, por tanto, asigna al Alcalde una misión primordial: mantener el orden público, lo que es equivalente a conservar el estado de normalidad en su $\mathrm{Mu}$ nicipio. A fin de garantizar este orden se le concede al Alcalde la posibilidad de tomar discrecionalmente las medidas que juzgue necesarias, con la obligación de dar cuenta a los órganos superiores: Ayuntamiento y Gobernador civil.

Las atribuciones que nuestra Ley de Régimen local asigna a nuestros Alcaldes vienen en definitiva completadas y desarrólladas en los artículos 3 y 7 de la vigente Ley de Orden Público. Así el artículo tercero de la misma dice: "El Gobierno, todas las Autoridades de la Nación y sus Agentes, velarán por la conservación del orden público. Su mantenimiento y defensa compete especial y directamente, en todo el territorio nacional, al Ministro de la Gobernación y, subordinadamente, dentro de cada Provincia, al respectivo Gobernador civil, y en cada Municipio, a su Alcalde". El artículo séptimo establece que: "Bajo la autoridad y dirección del Gobernador civil correspondiente, los Alcaldes coadyuvarán a la conservación del orden público en sus respectivos términos municipales; ejercerán en los Municipios que no sean Capitales de Provincia la autoridad gubernativa cuando el Gobernador civil no la asuma personalmente o por un delegado especial: y obrarán por propia iniciativa y responsabilidad cuando las circunstancias no les permitieran pedir o recibir instrucciones, dando cuenta de sus actos lo más rápidamente posible al Gobernador civil».

Este artículo séptimo le asigna un papel al Alcalde en materia de orden público, a primera vista menos importante que el que se le señala en el artículo 117 de la Ley de Régimen local, ya que los Alcaldes, según este artículo, serán coadyuvan tes del Gobernador civil en materia de orden público en sus 
términos municipales; sin embargo, se les autoriza a obrar por propia iniciativa y responsabilidad cuando las circunstancias no les permitieran pedir o recibir instrucciones.

A nuestro juicio, en la nueva Ley de Orden Público se tiende a que sea el Gobernador civil, como representante directo del Gobierno en la Provincia, el que vele por el orden público, y solamente cuando existiesen motivos graves que impidiesen al Alcalde comunicar rápidamente con el Gobernador civil, podrá aquél adoptar las medidas que en esta Ley se establecen.

El Alcalde, no obstante, sigue siendo la autoridad gubernativa en el Municipio, cuando el Gobernador civil no la asuma personalmente o por un Delegado especial. Por consiguiente, creemos que la Ley de Orden Público no disminuye en esta materia las facultades que los Alcaldes tenían en la legislación anterior, asignándoles la función de coadyuvar con los Gobernadores civiles cuando éstoś personalmente o por Delegados especiales ejerzan estas competencias.

No actuando el Gobernador o sus representantes, será siempre el Alcalde subsidiariamente el llamado a conservar el orden público. La Ley trata de prevenir posibles roces entre las distintas Autoridades, y se ve en su artículo séptimo ese deseo del legislador por mantener siempre la armonía entre los Organos de distinto rango, máxime cuando se trata de actuar en momentos tan críticos y decisivos como son los casos de perturbación del orden público.

\section{Sanciones de los actos contra el orden público}

E1 artículo 18 de la Ley actual recoge parcialmente el contenido del antiguo artículo con la misma numeración de la Ley de 28 de julio de 1933. La actual redacción de dicho artículo es la siguiente: "Las Autoridades gubernativas podrán sancionar los actos contra el orden público a que esta Ley se refiere, cualquiera que sea la forma de comisión, en la cuantía señalada en el artículo siguiente, sin perjuicio de la competencia de los Tribunales o Autoridades de otra jurisdicción". De poco serviría 
la imposición de obligaciones cívicas si su incumplimiento no fuese acompañado de una sanción. La coerción es esencial para que un ordenamiento jurídico tenga vigencia y efectividad práctica. Pensar otra cosa sería situarnos en un mundo que no sería el nuestro; equivaldría a atribuir a la actual sociedad una eticidad que está lejos de poseer, pues en definitiva el hombre, por su naturaleza caída, está propenso a la infracción del orden preestablecido.

Dignos de destacar son los artículos 19 y 21 de la Ley objeto de nuestra consideración, que parcialmente tenían su precedente en la antigua Ley de Orden Público, e indirectamente en nuestras leyes penales. Aunque someramente nos referimos a la materia que regulan los mismos, nos parece importante recoger las siguientes palabras del Preámbulo de la Ley, sumamente interesantes para la mejor comprensión de los artículos antes mencionados. Dice así el legislador: "Es, sin duda, destacada novedad la delimitación que se formula de las facultades sancionadoras de las Autoridades gubernativas en las infracciones que se cometan contra el orden público. El problema no es totalmente nuevo, pero vivía en varias disposiciones que, aunque poseian amparo en el artículo seiscientos tres del Código penal, carecían de sistema. Ahora se les confiere y dota de unidad, respetándose las garantías de legalidad penal clásicas en este Derecho. No sólo se fijan taxativamente las infracciones, sino también las autoridades que puedan sancionarlas, así como la cuantía de la sanción". Como desarrollo de estas palabras están los artículos 19 y siguientes de la Ley.

El artículo 19 establece :

1. Los Alcaldes podrán sancionar los actos contra el orden público con multas que no excedan de doscientas cincuenta pesetas en Municipios hasta diez mil habitantes; de quinientas pesetas, en los de 'diez mil a veinte mil; de mil pesetas, en los de más de veinte mil; de dos mil quinientas pesetas en los de más de cincuenta mil, y de cinco mil pesetas en los de más de cien mil.

2. Los Delegados del Gobierno en las Islas Canarias y Ba- 
leares podrán sancionar las mismas faltas con multas de hasta dos mil quinientas pesetas.

Este artículo, en la parte que hemos transcrito, constituye una novedad con respecto a la vieja Ley, ya que ésta omitía la facultad sancionadora de los Alcaldes. Sólo concedía posibilidad de imposición de multas al Ministro de la Gobernación y a los Gobernadores civiles, pero no se decía nada con respecto a los Alcaldes, pese a que también eran Autoridad gubernativa. Choca observar que los Alcaldes no tuviesen facultad sancionadora en un Estado constitucional democrático, como el entonces exis tente, que defendía plenamente la autonomía municipal. La nueva Ley no sólo concede a los Alcaldes la posibilidad de sancio. nar, sino que establece distintos tipos de sanción en atención al número de habitantes, consciente nuestro legislador de que la infracción de dicho orden es más grave cuanto mayor sea la población en que se produzca.

\section{Recursos contra estas sanciones}

El artículo 21-1. determina que: “contra las sanciones gubernativas sólo podrá el interesado interponer recurso, que tendrá el doble carácter de súplica ante la Autoridad que corrigió, y de alzada, ante el superior inmediato de aquéllan.

Se instituye en este primer párrafo un recurso con el doble carácter de súplica y alzada. Este recurso de súplica tiene un sentido sustancialmente distinto al que con el mismo nombre se establece en el artículo 122-3. ${ }^{\circ}$ de la Ley de Procedimiento administrativo de 17 de julio de 1958, ya que según este artículo la denominación de recurso de súplica es análoga a la de alzada ante el Consejo de Ministros o ante la Presidencia del Gobierno. El recurso de súplica que se regula en la Ley de Orden Público persigue una finalidad similar a la del recurso de reposición: nuevo examen de una resolución administrativa por la misma autoridad que la dictó. Por eso creemos se podía haber mantenido por el legislador la antigua denominación de recurso de reposición. 
Sin embargo, en este recurso, $y$ a tenor de lo dispuesto en el artículo 38 de la Ley de Jurisdicción Contencioso-administrativa y en el artículo 94 de de la Ley de Procedimiento administrativo, la Administración debe siempre dictar una resolución expresa, debidamente fundada. En cambio, en el recurso de súplica que la Ley de Orden Público establece, la Administración no tiene obligación de resolver como veremos posteriormente. No obstante, para nosotros, este recurso de súplica de que habla la Ley, es más semejante al recurso de reposición, en el sentido que, por ejemplo, se señala parcialmente en el artículo 377 de la Ley de Régimen local, pues este artículo, como dice el profesor Garrido Falla (Régimen de impugnación de los actos administrativos, pág. 343, Madrid, 1956) no deja lugar a dudas, ya que en él se configura el recurso de reposición como requisito previo indispensable "para interponer recursos o reclamaciones en los demás casos", y en esta expresión hay que considerar aludidos no sólo los recursos contenciosos, sino también los de alzada en vía jerárquica. No cabe duda que este recurso de súplica-alzada de que habla la Ley de Orden Público es de naturaleza administrativa, distinta a los recursos administrativos que regula nuestra Ley de Procedimiento administrativo. A nuestro juicio es criticable la técnica legislativa empleada por el legislador al introducir en nuestro ordenamiento un nuevo recurso con dos fases : súplica-alzada.

El párrafo $3 .^{\circ}$ del artículo 21 de la Ley objeto de nuestro estudio establece que "si se estimase totalmente como recurso de súplica, perdería su carácter subsidiario de recurso de alzada, pero si se desestimase total o parcialmente, o no fuese resuelto en el plazo de quince dias, la Autoridad sancionadora cursará el escrito en que se contenga al superior correspondiente, acompañando, a modo de informe, la resolución desestimatoria del recurso".

Según este apartado procede, por tanto, el recurso de alzada en los casos en que se desestime total o parcialmente el recurcurso de súplica. Estos casos ordinariamente serán los más, pues es difícil que la misma Autoridad rectifique tota!mente 
sus puntos de vista y satisfaga plenamente las pretensiones del recurrente. La ventaja que ofrece esta nueva modalidad del recurso de súplica-alzada sobre los clásicos recursos de reposición y alzada, es la rapidez en el procedimiento, ya que la no resolución en el plazo de quince días del recurso de súplica o su desestimación total o parcial, obligan a la Autoridad sancionadora a cursar el escrito del recurso al superior correspondiente.

$\mathrm{El}$ artículo 21 que comentamos dice en su párrafo $2 .^{\circ}$ : "El plazo de interposición de este recurso será el de diez días hábiles, a contar del siguiente al de la notificación de la sanción». A nuestro parecer bastaba conque hubiese dicho: "El plazo de interposición de este recurso será el de diez días". Según el artículo 60 de la Ley de Procedimiento administrativo, siempre que no se exprese otra cosa, cuando los plazos se señalen por días, se entiende que éstos son hábiles, excluyéndose del cómputo los feriados. Por otra parte, de acuerdo con el artículo 59 de la misma Ley, los plazos se contarán siempre a partir del día siguiente a aquél en que tenga lugar la notificación o publicación del acto de que se trate.

El párrafo $4 .^{\circ}$ de dicho artículo 21 establece que "para recurrir contra la imposición de una multa como sanción gubernativa, se verificará previamente el depósio del tercio de su cuantía, salvo los casos de notoria incapacidad económica apreciada por la Autoridad que sancionón. Vemos aquí una derogación parcial al principio de ejecutividad del acto administrativo y a la regla solve et repete, según la cual la impugnación de un acto administrativo que implique liquidación de un crédito a favor del Estado sólo es posible si el particular se aviene previamente a realizar el pago que se discute. Podemos incluso afirmar que el principio de ejecutividad queda totalmente derogado cuando el sancionado tiene notoria incapacidad económica, si bien se ha de advertir que por ser la Autoridad sancionadora quien apreciará la misma, ésta lógicamente actuará con criterio restrictivo.

El párrafo $5 .^{\circ}$ del mencionado artículo determina que para la resolución de los recursos de alzada son superiores de los Al- 
caldes y Delegados del Gobierno en las Provincias insulares los Gobernadores civiles respectivos. Estos representan al Gobierno en la Provincia y aquéllos lo representan en las Entidades municipales. Por consiguiente, en este tercer grupo de atribuciones que nuestra legislación local señala a los Alcaldes, existe una subordinación de los mismos de primer grado con respecto al Gobernador civil, y de segundo grado con relación al Gobierno.

El artículo $22-1 .^{\circ}$ de la repetida Ley de Orden Público dice: "Una vez firme la resolución por no haberse interpuesto contra ella recurso o ser este desestimado, si la multa no estuviere abonada, los Gobernadores civiles, el Director General de Seguridad o el Ministro de la Gobernación podrán disponer del arresto supletorio del infractor hasta treinta días, o bien oficiar al Juzgado competente con copia auténtica de la resolución, para que proceda a su exacción por la vía de apremio o, en su caso, a la declaración de insolvencia total o parcial del multado, o imposición de arresto supletorio que proceda, que no podrá exceder de treinta dias". Se puede observar en este texto que el legislador no respeta plenamente la diferenciación y separación de los tres poderes clásicos. Quizás se haya procedido así con el fin de robustecer en estos casos excepcionales el poder gubernativo. A primera vista existe una derogación parcial del párrafo segundo del artículo 18 del Fuero de los Españoles, si bien este precepto que se comenta encuentra plena justificación en el párrafo $10^{\circ}$ del mismo artículo, cuando dice: "Ningún español podrá ser detenido sino en los casos y en la forma que prescriben las leyes").

Con el fin de que las multas que a tenor del artículo 19 se impongan no queden sin efectividad, el artículo $22-2 .^{\circ}$ de esta Ley dice: "Los Alcaldes y Delegados del Gobierno darán cuenta a los Gobernadores respectivos de la falta de pago de las multas que hubieren impuesto a los efectos del párrafo anterior". 


\section{LOS ESTADOS DE EXCEPCIÓN Y GUERRA}

En el capítulo III relativo al estado de excepción, se dice en el artículo 33 : "Uno. $\rightarrow \mathrm{Si}$ algún funcionario o persona al servicio del Estado, Provincia, Municipio y Entidad o Instituto de carácter público u oficial, favoreciese con su conducta la actuación de los elementos perturbadores del orden o se negare a cooperar con la Autoridad constituída, cuando le fuere expresamente reclamado, podrá ser suspendido provisionalmente por ésta de su empleo, cargo o función y sueldo anejos en tanto duren las circunstancias, sin que contra dicha resolución quepa recurso alguno. Dos.-Además se pasará el tanto de culpa a la Autoridad judicial correspondiente y se notificará al superior jerárquico a los efectos de oportuno expediente disciplinarion.

En las situaciones de crisis se requiere, por tanto, una incondicional colaboración de los funcionarios o personal al servicio, en nuestro caso concreto, del Municipio y se sanciona convenientemente la falta de esta ayuda. Es lógico que las Entidades públicas cuenten con sus empleados, si fuera preciso, en aqu llos momentos de gravedad para la comunidad nacional. En muchas ocasiones el Estado se verá obligado a pedir al personal al servicios de los Entes estatales o paraestatales una cooperación activa por convenir así al fin público. Por eso, el artículo antes mencionado sanciona esta falta de cooperación cuando fuere reclamada. Además, en este mismo artículo se castiga a los funcionarios que favoreciesen con su conducta la actuación de los elementos pertubadores del orden. La sanción en este caso es obvia y no exige comentario; si siempre los Entes públicos han de exigir a sus empleados la máxima lealtad, no cabe duda que el quebrantamiento de ésta adquiere un matiz mucho más grave en circunstancias de anormalidad.

Declarado el estado de excepción, las sanciones son también más graves. Así el artículo 34 dispone: "Las Autoridades podrán sancionar los actos contra el orden público, con multas su- 
periores en un cincuenta por ciento a lo autorizado en el capítulo segundon.

En el capitulo IV de esta Ley a que repetidamente venimos refiriéndonos, se determinan en el artículo 35 los supuestos en los que se puede declarar el estado de guerra. Esta declaración corresponde realizarla siempre a la Autoridad gubernativa. El artículo 38 dice que "si los hechos ocurrieren en Capital de Provincia, la Autoridad gubernativa, para los efectos del artículo anterior, lo será el Gobernador civil, la Autoridad militar la que correspondiera hacerse cargo del mando, y la judicial la superior en orden jerárquico. En los demás pueblos, cuando el peligro fuere inminente y no pudiera acudirse al Gobernador civil, se reunirán para dicha declaración el Alcalde o el Delegado del Gobierno en las Provincias insulares, el Juez de Primera Instancia y el Jefe militar de mayor graduación con mando de armas, o, en su defecto, de organismo o dependencia militar".

Se puede observar que este artículo tiene su precedente en el artículo 51 de la Ley de 1933. Sin embargo, la actual redacción es más precisa y ofrece a primera vista una mayor claridad. En la antigua Ley se hablaba unas veces de Autoridad civil y otras de Autoridad gubernativa. La Comisión redactora del nuevo texto de la Ley ha preferido mantener siempre la denominación de Autoridad gubernativa, tanto al referirse a las situaciones de normalidad, como a los estados de excepción y guerra. Creemos que éste es un acierto de nuestro legislador actual, ya que en la antigua redacción de este artículo se daba el contrasentido de que Autoridades civiles eran también los militares superiores jerárquicos, en la Provincia o pueblo de que se tratase.

La disposición final segunda de esta Ley autoriza al Ministerio de la Gobernación y, en su caso, al Gobierno, para dictar las normas reglamentarias que pueda exigir la ejecución de los preceptos de esta Ley. Comenzó la misma a regir el día uno del pasado mes de septiembre. Hasta la fecha no se ha dictado ningu. na disposición reglamentaria sobre la misma. Es corto aún el período que lleva de vigencia y lógicamente su aplicación no ha planteado problemas de importancia. No cabe duda que con el 
transcurso del tiempo y cuando circunstancias más o menos críticas exijan su aplicación, aparecerán estas normas reglamentarias, previstas en la disposición final antes mencionada, tendentes principalmente a evitar, como decía el Ministro de la Gobernación en la presentación de la Ley a las Cortes, que sea Ley sin vigencia efectiva o de la que se permitan burlas impunes.

\section{CONCLUSión}

Para finalizar nuestro trabajo sobre las facultades de los Alcaldes en la nueva Ley de Orden Público, podemos decir que la misma recoge las facultades que en la antigua legislación se les concedían a los Alcaldes, con la ventaja de que la nueva sistematización es más clara. A través del análisis realizado hemos visto el papel primordial que juegan los Alcaldes o los Delegados del Gobierno en las Provincias insulares en la Ley a que en este estudio nos venimos refiriendo.

Se hace de dichas atribuciones una regulación adaptada a las nuevas y modernas técnicas ofrecidas por la doctrina jurídicoadministrativa, introduciéndose algunas facultades más. Se recogen preceptos dispersos referentes a esta materia, y concretamente aparece bastante perfecta la delimitación que se hace de las facultades sancionadoras de los Alcaldes. La vieja Ley, si bien consideraba a éstos como Autoridad gubernativa, no les atribuía funciones sancionadoras. Correspondía la facultad de sanción solamente al Ministro de la Gobernación y a los Gobernadores civiles. Con arteglo al artículo 19 de la Ley vigente, también los Alcaldes podrán sancionar con multas graduables, teniendo en cuenta en su fijación el número de habitantes que la población en cuestión tenga.

Aunque no estamos de acuerdo con la denominación que se da en el artículo 21 al recurso de súplica, creemos que salvando estas pequeñas diferencias y dejando a un lado ciertas discrepancias que a lo largo del trabajo hemos anotado en relación con la articulación del texto de la Ley, nos parece la nueva Ley 
de Orden Público en su conjunto plenamente lograda; cuya revisión se imponía dada la antigüedad de la vieja Ley, los cambios operados en las bases de la convivencia social y teniendo en cuenta las conquistas que en el campo del Derecho público se han obtenido modernamente.

Son amplias las facultades que a los Alcaldes se les concede en la Ley, pero no olvidemos la grave responsabilidad que éstos contraen ante la sociedad por su imperfecta aplicación. Se trata, como dijo el Ministro de la Gobernación en el discurso de presentación de la Ley ante las Cortes Españolas, de la Carta magna de la convivencia social. Es natural, por tanto, que en su efectiva aplicación pongan las Autoridades gubernativas, y concretamente los Alcaldes, su mayor empeño. 